\title{
ALUMINOTHERMIC PRODUCTION OF TITANIUM ALLOYS (PART 2): IMPACT OF ACTIVATED RUTILE ON PROCESS SUSTAINABILITY
}

\author{
S. Hassan-Pour ${ }^{1 *}$, C. Vonderstein ${ }^{1}$, M. Achimovičová, ${ }^{2,3}$, V. Vogt ${ }^{2}$, \\ E. Gock $^{2}$, B. Friedrich ${ }^{1}$ \\ ${ }^{1}$ IME Process Metallurgy and Metal Recycling, RWTH Aachen University, \\ Intzestrasse 3, 52056 Germany \\ ${ }^{2}$ Institute of Mineral and Waste Processing, Waste Disposal and Geomechanics, \\ Technical University-Clausthal, Walther-Nernst-Str. 9, 38678 Germany \\ ${ }^{3}$ Institute of Geotechnics, Slovak Academy of Sciences, Košice, Watsonova \\ 45, 04353 Slovakia
}

Received 29.12.2015

Accepted 03.06.2015

\begin{abstract}
The aluminothermic process provides a cost-reduced production method for titanium and titanium alloys by reduction of $\mathrm{TiO}_{2}$ with subsequent refining by electroslag remelting The aluminothermy involves high heating rates, high temperatures and short reactions times combined with a self-propagating behaviour of the reaction. By co-reduction of $\mathrm{TiO}_{2}$ and oxides of alloying elements such as vanadium pentoxide, direct synthesis of a titanium alloy is possible. The use of rutile ore concentrates causes a further reduction of process steps. In order to charge rutile ore complex thermodynamic calculations are required taking enthalpy input of various bycomponents into account.

The aluminothermic reduction is conventionally enhanced by a highly heatproviding reaction based on the reduction of $\mathrm{KClO}_{4}$. In order to minimize the use of chlorine-based products extensive studies are made to investigate the feasibility of using mechanically activated rutile as input material for the aluminothermic process. Due to the mechanical activation the intrinsic enthalpy of the reaction is increased thus facilitates a process with reduced amount of $\mathrm{KClO}_{4}$. A major challenge represents the determination of a compromise between low activation duration and reduced $\mathrm{KClO}_{4}$ amount. In order to define the process window parameters like intrinsic chemical energy (enthalpy of the reaction mixture), equilibrium temperature and physical properties
\end{abstract}

* Corresponding author: S. Hassan-Pour, SHassanPour@metallurgie.rwth-aachen.de 
(particle size and mixing degree) were optimized. After adjusting the process parameters it is possible to save up to $42 \% \mathrm{KClO}_{4}$ for the ATR reaction with $2 \mathrm{~h}$ activated input material. This reduction of $\mathrm{KClO}_{4}$ material affects a decrease of the produced gaseous compounds and the subsequent off-gas cleaning system

Keywords: aluminothermic reduction, ilmenite, mechanical activation, titanium alloys

\section{Introduction}

Titanium alloys are widely used in high temperature structural applications in the aerospace or automotive industry. Due to their good corrosion resistance, their low density and promising mechanical properties at high temperatures they are applied especially in aircrafts and aircraft engines. In order to reduce the high material and production costs alternative production processes are highly demanded. The aluminothermic process offers great potential to replace the Kroll-Process and provides a least expensive production method for the direct synthesis of titanium alloys. The high oxygen solubility of titanium does not allow producing titanium alloys with low aluminium and oxygen contents (below $500 \mathrm{ppm}$ ) at the same time [1]. In order to produce low-alloyed titanium materials such as Ti-6Al-4V that represents the most utilized titanium alloy the main research area includes the manufacturing of a master alloy. It has been proofed that the aluminothermic co-reduction of various oxides targeting to master alloy like Ti-Nb-Al is feasible [9,10]. The aluminothermic production of TiAl as well as Ti-Nb-Al has been successful charging $\mathrm{TiO}_{2}$ as synthesized pigment $[9,10]$.

Considering the entire production process of titanium the production of $\mathrm{TiO}_{2}$ pigment requires chlorination and distillation. Charging rutile ore would represent a minimizing of the production steps. Furthermore the use of rutile ore is more attractive concerning economic and resource efficiency issues. Rutile ore contains by-components either adding enthalpy to the entire reactions as $\mathrm{Fe}_{2} \mathrm{O}_{3}$ and $\mathrm{V}_{2} \mathrm{O}_{5}$ or consuming enthalpy as $\mathrm{ZrO}_{2}$ and $\mathrm{Al}_{2} \mathrm{O}_{3}$.

The consideration of additional enthalpy given by mechanically activated material to the aluminothermic reaction is proved to be extraordinary difficult. This additional heat is causing certainly a reduction of the amount of $\mathrm{KClO}_{4}$ within the process. However a predetermination of specified quantity of decreased $\mathrm{KClO}_{4}$ is not possible. The required activation degree in order to carry out the aluminothermic reaction is not predictable as well. The major challenge is to determine a compromise between a reasonable activation duration and maximum saving of $\mathrm{KClO}_{4}$ input. Due to the changed physical properties caused by mechanical activation other parameters of the process as to be adjusted. This determination requires extensive examination that is explained within the next chapters.

\section{Fundamentals}

\section{Mechanical Activation}

In order to detect mechanical activation of rutile fine structure X-ray analysis are applied. The ratio of X-ray diffraction intensities $\mathrm{I} / \mathrm{I}_{0}$ at the lattice plane 110 of rutile is measured whereas $I_{0}$ is the measured value for the untreated material (defined as $100 \%$ $<10 \mu \mathrm{m})$ and $\mathrm{I}$ is the mechanically treated material. The ratio $\mathrm{I} / \mathrm{I}_{0}$ is a parameter that illustrates information about grain size, lattice defects and solid state reactions. 
A further method to investigate the crystalline structure with displaying the dependency of the mechanical treatment is infrared spectroscopy (IR). In general inorganic material holds just a few wide adsorption bands. Structural groups with homopolar bounding components are infra-red active. Defects in the bounding cause a change in the amount, the position and in the intensity of the absorption bands. Vibration milling of mineral raw material effects via energy dissipation extreme short punctual temperature peaks that induces plasmatic conditions and leads to a thermal dissociation. These lattice defects are measured for example by susceptibility method that offers the possibility detecting changes in paramagnetism. At large element deficits metastable transition are formed that effects an increase in solubility.

Depending on the number of solid phases involved, solid state reactions by mechanical activation are classified into single and multi-phase systems. Table 1 shows referred solid-state reactions of the Ti-System [2-7]. Solid state reactions in single-phase systems are either defect reactions (homogeneous reactions) or intersolid diffusions with concentration gradients (inhomogeneous reactions). Solid state reactions of multi-phase systems are characterized by the fact that the mass transport takes place across phase boundaries by means of diffusion under formation of one or more product phases (heterogeneous reactions).

Table 1. Solid state reactions carried out by mechanical activation

\begin{tabular}{|c|c|c|c|}
\hline Type of reaction & \multicolumn{3}{|c|}{ example } \\
\hline $\begin{array}{l}\text { Homogeneous } \\
\text { reaction }\end{array}$ & $\gamma-\mathrm{TiO}$ & $\stackrel{\beta}{\longrightarrow} \alpha-\mathrm{TiO}_{2}$ & {$[1]$} \\
\hline $\begin{array}{l}\text { Inhomogeneous } \\
\text { reaction }\end{array}$ & $\alpha-\mathrm{TiO}_{2}$ & $\stackrel{\beta}{\longrightarrow} \alpha-\mathrm{TiO}_{2-x}$ & [2] \\
\hline $\begin{array}{l}\text { Heterogeneous } \\
\text { reaction }\end{array}$ & $\begin{array}{l}2 \mathrm{FeTiO}_{3}+2,5 \mathrm{O}_{2} \\
x \mathrm{FeTiO} \\
3 \mathrm{AAl} \\
\mathrm{TiO}_{2}+\mathrm{MgO} \\
\mathrm{Ti}+\mathrm{H}_{2}\end{array}$ & $\begin{array}{l}\longrightarrow 2 \mathrm{TiO}_{2}+\mathrm{Fe}_{2} \mathrm{O}_{3} \\
\stackrel{\mathrm{Ar}}{\longrightarrow} \mathrm{Al}_{2} \mathrm{O}_{3}+\mathrm{TiO}+\mathrm{Fe}_{2} \mathrm{Ti} \\
\longrightarrow \mathrm{MgTiO}_{3} \\
\longleftrightarrow \mathrm{TiH}_{2}\end{array}$ & $\begin{array}{l}{[3]} \\
{[4]} \\
{[5]} \\
{[6]}\end{array}$ \\
\hline
\end{tabular}

$\gamma$ : amorphous $\mathrm{TiO}_{2}, \beta$ : Anatase, $\alpha$ : Rutile

\section{Aluminothermic Reduction}

An aluminothermic reaction is defined as the reduction of a metal compound in which aluminum is used as reducing agent. The feasibility of the reaction is given when aluminum has a greater affinity for the non-metal element of the compound than the desired metal. Usually aluminothermic processes are applied to manufacture master alloys for the steel and superalloy industries by reducing mostly refractory metal oxides or ores offering a carbon-free production method. The greater the difference in oxygen affinity of aluminum and metal oxide, the higher is the ease of reaction. Regarding the reduction of $\mathrm{TiO}_{2}$ with aluminum the intrinsic heat of the reaction is not sufficient to maintain the reaction self-sustained. Therefore, booster are added to reach the needed energy density. Different rules are expressed predicting the reaction behavior depending on the heat of the reaction produced by either one gram of the reaction or by one mol of 
active reaction metal in the reaction mixture [8]. It seems also reasonable to consider the process temperature to evaluate the process behavior. Therefore, the calculation of the aluminothermic mixture needs input parameters like the required energy density, targeted adiabatic temperature and estimated heat losses. In order to reach the targeted temperature changes in the mixture are not allowed to effect or vary the product alloy composition. This modelling of the reaction mixture is reported in $[9,10]$. The process window of aluminothermic reactions has to be defined very clearly because a narrow difference in the energy density of 50 to $100 \mathrm{~J} / \mathrm{g}$ could change the reaction from a slow reaction propagation and early solidification to a fast reaction propagation with strong turbulences.

The use of rutile ore makes this calculation more complex. Table 2 gives an overview of the reduction reaction of the by-components included in rutile ore. The heats of these reactions differ significantly. Although the percentages of these bycomponents are not very high the released heats of each reaction have to be taken into account due to the above explained narrow process window.

Table 2. Heats of reduction per mole oxide

\begin{tabular}{|c|c|}
\hline Reaction eq. & $-\Delta \mathbf{H}_{\mathbf{R}}{ }^{0}$ in $\mathrm{kJ}$ \\
\hline$F_{2} O_{5}+10 F 3 A l \rightarrow 2 \mathrm{~F}+5 / 3 \mathrm{Al}_{2} \theta_{3}$ & 1242.2 \\
\hline$S i O_{2}+4 F 3 \mathrm{Al} \rightarrow S i+2 F 3 A l_{2} O_{9}$ & 206.4 \\
\hline $\mathrm{Fe}_{2} \mathrm{O}_{3}+2 \mathrm{Al} \rightarrow 2 \mathrm{Fe}+A l_{2} \mathrm{O}_{3}$ & 849.9 \\
\hline $\mathrm{Cr}_{2} \mathrm{O}_{3}+2 \mathrm{Al} \rightarrow 2 \mathrm{Cr}+\mathrm{Al}_{2} \mathrm{O}_{3}$ & 548.5 \\
\hline$Z r O_{2 \mathrm{z}}+4 / 3 \mathrm{Al} \rightarrow \mathrm{Zr}+2 / 3 \mathrm{Al} \mathrm{l}_{2} \mathrm{O}_{\mathrm{g}}$ & 19.6 \\
\hline$N b_{2} U_{5}+10 / 5 A l \rightarrow 2 \mathrm{Nb}+5 / 5 A l_{2} U_{9}$ & 893.2 \\
\hline$M n Q+2 / 3 A l \rightarrow M n+1 / 3 A_{2} O_{3}$ & 173.6 \\
\hline
\end{tabular}

The reduction of several by-components is more favorable than the reduction of titanium dioxide thus remaining within the metal phase. Therefore the master alloy has to be chosen very carefully in order to achieve the requirements for the Titanium alloy Ti-6Al-4V. Therefore the composition of the master alloy is Ti with $60 \mathrm{wt} .-\%$, Al with $24 \mathrm{wt} .-\%$ and $\mathrm{V} 16 \mathrm{wt} .-\%$. The main focus within this investigation is the determination of the required energy charging mechanically activated material for the aluminothermic reaction. It has to be balanced out how much Booster can be saved by charging a reasonable activation of the rutile minimizing the introduced energy for milling and maximizing the saved amount of booster.

\section{Experimental work}

\section{Mechanical activation}

The available investigations for mechanical activation focus on the impact of solubility of hardly soluble metal compounds regarding a hydrometallurgical technology for metal extraction. The most important results are given by Boldyrev and Baláž [11,12]. 
The main problem for the technical application of mechanical activation is an appropriate milling device. In order to initiate the mechanical activation impact loading is required. This mechanism is realized in vibration mills that are available in any scale. Many investigations of mechanical activation are carried out in lab scale mills working within the centrifugal field obtaining the impact loading by pressure. However there are no industrial scale mill of this mill type available.

For the mechanical activation of rutile for the synthesis of Ti-Al-V alloys via aluminothermic reaction eccentric vibrating mill (Type ESM 656-0.5 ks Siebtechnik GmbH Germany) is used. The eccentric vibrating mill is a one-pipe mill with modular structure. Figure 1 shows the structure of eccentric vibrating mill. The eccentric vibrating mill has one cylindrical grinding vessel (1) with grinding elements (4), to which is solidly attached the exciter unit (2). The exciter unit is excited eccentrically on one side that is outside the gravity axis and the mass center of the grinding container. The exciter mass is balanced by a parallel counterweight (3) disposed on the opposite side of the grinding container. The cylindrical grinding vessel in welded construction is mounted on helical springs which are resting on the base frame. Both grinding container ends are closed with bolted on covers, one of which is fitted with an inspection cover. The material to be ground is fed into the mill via a flanged connection at the highest point of the container. Ground material is discharged via an outlet in one of the covers. This outlet is fitted with a perforated plate, to retain the grinding elements inside the container. Drive of the mill is a 3-phase motor (7) via a cardan shaft (8). The inhomogeneous vibrations are generated by the exciter unit in form of the bearing pedestal with adjustable eccentric weights (6). The exciter unit (5) is laterally flange mounted, with the counterweight on the opposing side also flange mounted [13].
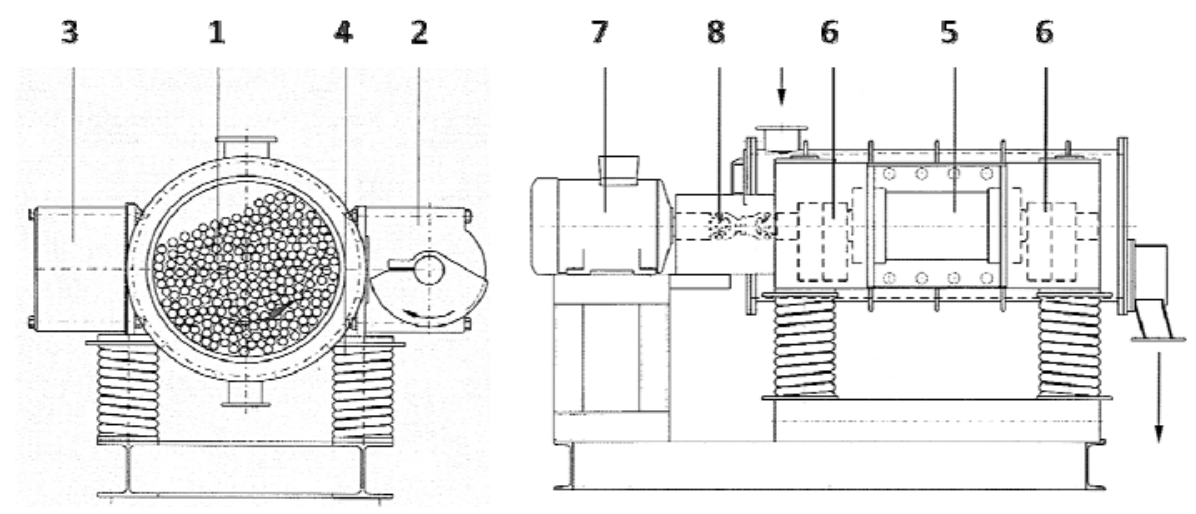

Fig. 1. Structure of eccentric vibrating mill [13]

As input material rutile concentrate is used with the following composition $57 \% \mathrm{Ti}, 0.7 \% \mathrm{Zr}, 0.7 \% \mathrm{Fe}, 0.3 \% \mathrm{Nb}, 0.2 \% \mathrm{Si}, 0.1 \% \mathrm{Al}, 0.1 \% \mathrm{Cr},<0.03 \% \mathrm{P}$, $<0.03 \% \mathrm{~S}$. The analysis via diffractometer shows only rutile modification. Other bycomponents could not be detected.

\section{Aluminothermic Reduction}

The aluminothermic reactions have been conducted in different scales. The preliminary trials are conducted in ceramic mullite based crucibles with a input mixture 
of $1,06 \mathrm{~kg}$. Since the impact of heat losses on the reaction behavior in this small scale is significant the focus of the preliminary trials lies on the general feasibility of a substitution of $\mathrm{KClO}_{4}$ with activated material. The other scales are conducted in small reactors with a refractory lining based on alumina. The initial ignition is carried out by an electrical ignition on top of the input mixture in all trials. Table 3 gives an overview of the conducted trial scales with the targeted amount of alloy product. In order to investigate the product quality the aluminothermic reaction is carried out with an upscale factor 5 with the defined parameters during the experimental work.

Table 3. Experimental scale of aluminothermic trials

\begin{tabular}{|r|r|r|} 
& $\begin{array}{l}\text { Charge of mix } \\
\text { in } \mathrm{kg}\end{array}$ & $\begin{array}{l}\text { Alloy Product } \\
\text { in kg }\end{array}$ \\
\hline preliminary trials & 1.060 & 0.385 \\
\hline small scale & 8.440 & 2.950 \\
\hline mid scale & 18.219 & 5.900 \\
\hline scale-up & 90.759 & 29.500
\end{tabular}

For the evaluation of the aluminothermic trials the visual observation of the reaction procedure is as important as the analysis of the chemical composition of the ATR product. The visual evaluation includes the degree of turbulence during reaction and amount of released dust, smoke and reaction mixture. Furthermore parameters like reaction time, measured from finished ignition to strongly decrease of smoke formation, and droplet loss that considers the metal amount distributed within the slag phase are introduced to evaluate the trials. The slag and metal phases are inspected under following aspects: porosity, recovery and purity concerning metal droplets and slag inclusions. Afterwards the metal is analysed for chemical composition and oxygen content.

In order to determine the impact of mechanical activation on the ATR reaction following procedure is conducted within the preliminary trials. In order to observe an effect of higher intrinsic enthalpy of the mixture the energy density of the aluminothermic reaction of a non-activated rutile is decreased to the limit of selfpropagating. The energy density for this case is determined to be $2400 \mathrm{~J} / \mathrm{g}$. The reaction time was $120 \mathrm{~s}$ with a high amount of unreacted material at top of the mixture. The slow reaction result in a metal recovery of $62.8 \%$. This reduced energy density is applied for a reaction with rutile that is mechanically activated for $3 \mathrm{~h}$. The reaction was finished within $85 \mathrm{~s}$ with evidently stronger turbulence and higher amount of released reaction mixture. Whereas unreacted material could be find at the mixture surface with nonactivated rutile the upper part of the trial with activated rutile was not full reacted but in a sintering stage. However the metal recovery was not increased. Based on the promising results of the preliminary trials further trials are conducted in small and mid scale with a variation the reaction parameters as activation duration, $\mathrm{Al}$ grain size and $\mathrm{KClO}_{4}$-addition. The selected range for variation of each reaction parameter is shown in figure 2 . 
Activation duration

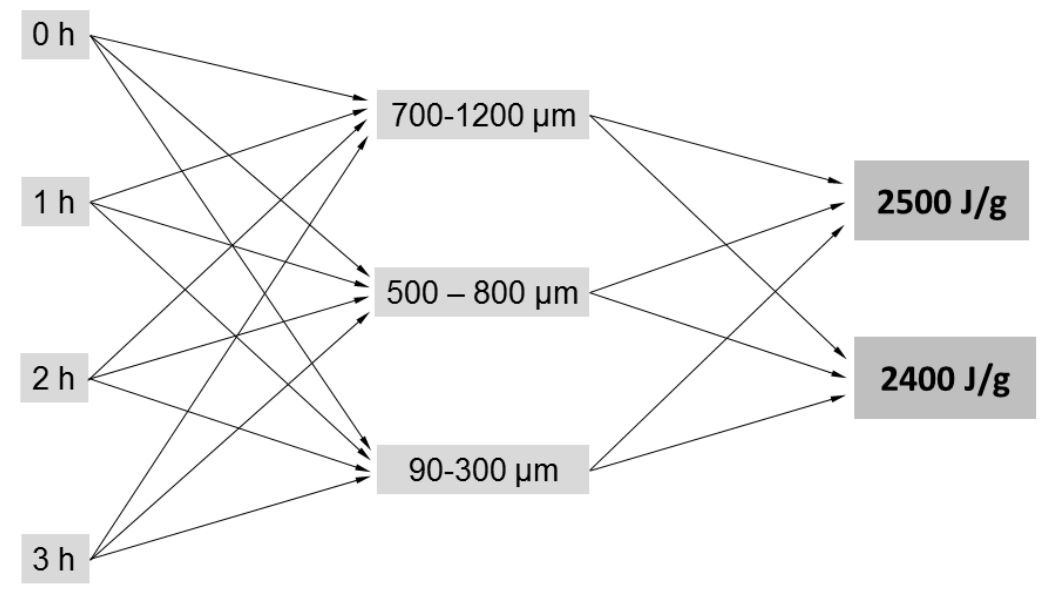

Fig. 2. Variation of trial parameters for ATR experiments

The activation duration is varied between $0 \mathrm{~h}, 1 \mathrm{~h}, 2 \mathrm{~h}$ and $3 \mathrm{~h}$, whereas $0 \mathrm{~h}$ stays for non-activated rutile. Previous investigations showed that the use of Al-grid with a size between 500-800 $\mu \mathrm{m}$ generates the best results for $\mathrm{TiO}_{2}$ pigment. For the present work the investigations have done with range of particle size both bigger and smaller. The used rutile has particle size within the range $125-180 \mu \mathrm{m}$. Based on the out coming of the pretrial the determined energy density of $2400 \mathrm{~J} / \mathrm{g}$ and $2500 \mathrm{~J} / \mathrm{g}$ is applied for the further experiments.

\section{Results and discussion}

In order to identify the reaction ability of the mechanical activated rutile at the aluminothermic reaction the activation degree is measured. Figure 3 shows the activation degree of the charged rutile concentrate depending on the specific energy consumption. The activation degree is measured at lattice plane 110. For the aluminothermic trials the activated material is classified in activation duration $1 \mathrm{~h}, 2 \mathrm{~h}$ and $3 \mathrm{~h}$. The activation degree decreases from 0.7 to 0.25 with an increase of the duration from $1 \mathrm{~h}$ to $3 \mathrm{~h}$. 


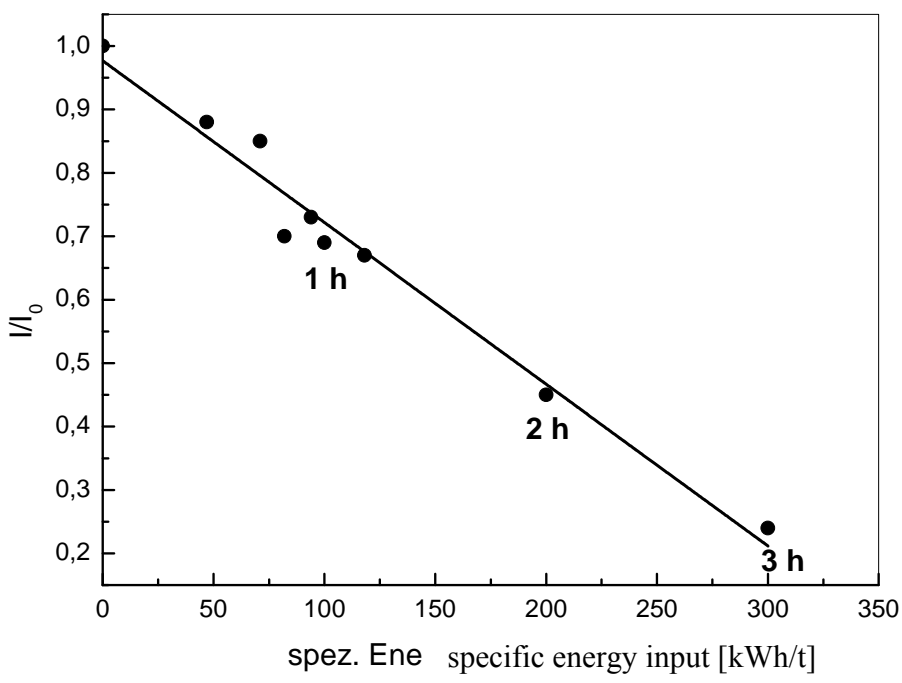

Fig. 3. Activation degree of charged rutile concentrate vs. specific energy input

Influence of activation duration on booster demand and metal recovery

In order to compare the ATR trials with different activation degrees other reaction parameters are kept constant. The following trials are conducted in mid scale and with fine Al material. The aim is to reach comparable or even better results with activated rutile with lower amount of $\mathrm{KClO}_{4}$ than with non-activated rutile that requires an energy density of $2800 \mathrm{~J} / \mathrm{g}$. Figure 4 shows the normalized metal recovery of four trials with the variation of intrinsic energy of the reaction. The energy density for the experiments with activated rutile is adjusted to $2500 \mathrm{~J} / \mathrm{g}$ except trial A3 with $3 \mathrm{~h}$ activation that has $2400 \mathrm{~J} / \mathrm{g}$. Because of the extreme turbulence and strong reactivity of the material the energy density could not be further increased to $2500 \mathrm{~J} / \mathrm{g}$. These 3 trials are compared to trial A0 non-activated rutile with an energy density of $2700 \mathrm{~J} / \mathrm{g}$. 


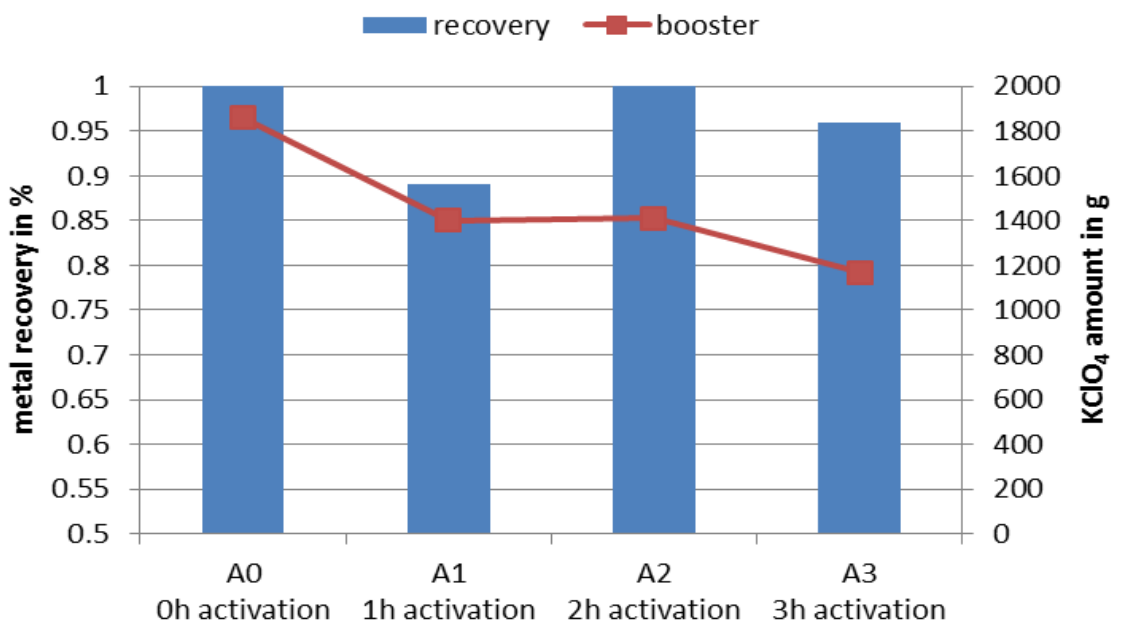

Fig. 4. Normalized metal recovery of ATR trials with different activation duration

Figure 4 shows, that $1 \mathrm{~h}$ activation is not enough to reach results as good as without activated rutile. For the experiment with $2400 \mathrm{~J} / \mathrm{g}$ the metal recovery amounts to just $49 \%$. But it is notable that at this energy level no reaction is feasible with nonactivated material. However the ATR product with $1 \mathrm{~h}$ activation is not satisfying. The comparison in figure 4 shows that $2 \mathrm{~h}$ activation results in a same reaction propagation like non-activated ATR trials with more booster. Though Trial A2 has $500 \mathrm{~g}$ less $\mathrm{KClO}_{4}$ within the mixture compared to A0 the produced metal has the same amount. Trial A3 has even $663 \mathrm{~g}$ less booster than A0 and offers a comparable ATR process. It seems that $2 \mathrm{~h}$ of mechanical activation promises good results that are equal to ATR trials that are not activated. By using $2 \mathrm{~h}$ activated rutile substitution of $500 \mathrm{~g}$ booster is possible that represents a reduction of booster of $32 \%$. A3 would even result in a booster reduction of $42 \%$.

\section{Influence of Al-Grain Size}

Beside other above explained effects the mechanical activation causes a reduction of the particle size. As reported especially in combustion reactions the influence of particle size on the reaction propagation is given not by one reactant but by the ratio of the reactants. Because the particle size of aluminum has also a kinetic effect on the reaction propagation it seems reasonable for the present work to vary the particle size of aluminum as well. This effect arises due to the formation of an interconnected network of the low melting point reactant which enhances the reaction [14]. For the investigation of the influence of aluminum particle on the reaction process the reaction time is measured. This parameter allows to have an overview about the reaction behavior. Long reaction times indicate low product quality because solidification starts at an early stage of the reaction and the separation of metal-slag is not sufficient [15]. Figure 5 shows the measured reaction time of 23 different trials sorted by the particle sizes of aluminum and activation duration. 


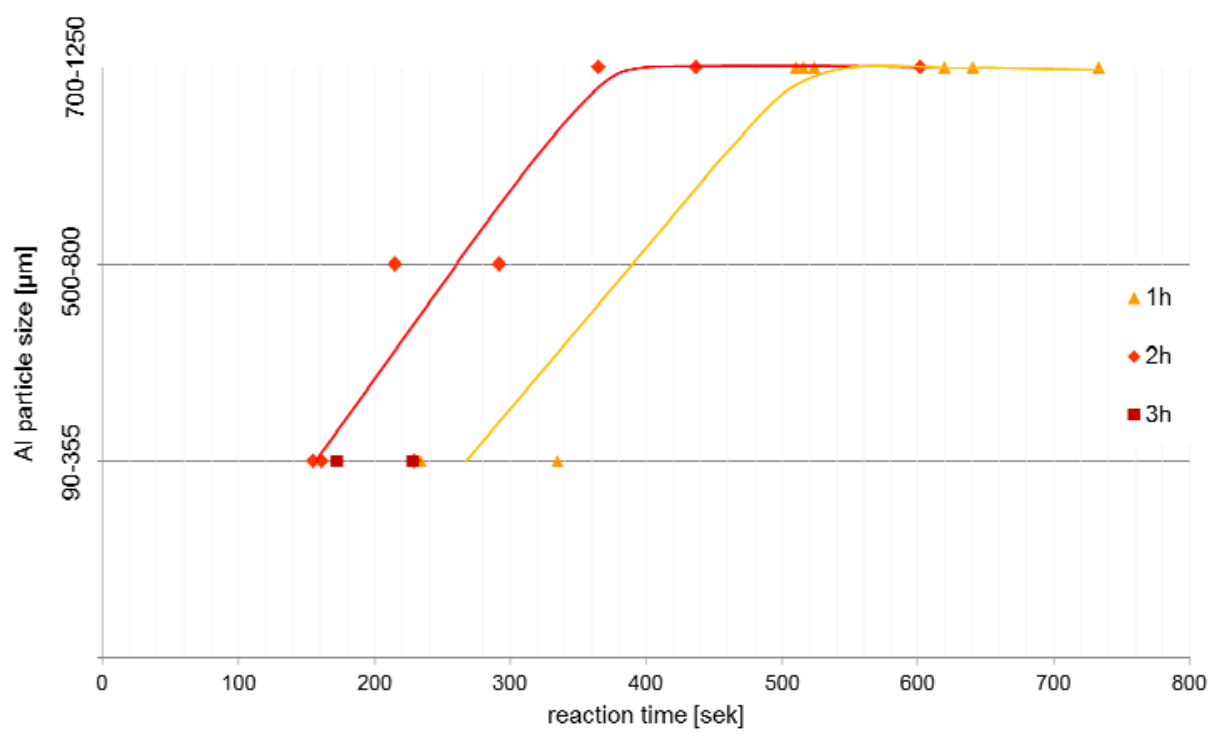

Fig. 5. Particle size of aluminum vs. reaction time

In figure 5 it is noticeable that a terrace formation occurs from coarse aluminum and long reaction times to fine $\mathrm{Al}$ particles and short reaction times. Furthermore, the measured reaction times show a wide deviation whereas the trials with fine Al shows the smallest deviation with $3 \mathrm{~min}$, the trials with coarse aluminum spread even over 6 min. It makes clear that fine aluminum accelerates the reaction disregarded other reaction conditions. Regarding trails with $1 \mathrm{~h}$ and $2 \mathrm{~h}$ activation, the trend line is plotted in fig. 5. It can be seen, that trend line for $2 \mathrm{~h}$ has a steep slope

\section{Impact of experimental scales on metal yield}

The experimental scale of aluminothermic trials has a strong influence of the heat transfer during the reaction. Aluminothermic reactions are autothermic processes and the released heat enforces the self-sustaining propagation behavior of the reaction. The refractory linings at the reactor wall consume a high amount of heat. By decreasing the ratio of area of reactor wall to area of released reaction heat the heat loss is significantly decreased. Therefore the heat loss in large scale of ATR trials is less of consequence than in small scale trials. In order to offer reliable results it is necessary to proof the parameters in large scale trials. Because trials with $2 \mathrm{~h}$ activation time and fine aluminum particles have shown the best reaction behavior concerning reaction propagation, reaction velocity and adequate temperature raise with a good slag-metal separation, an up-scale with a scale factor of 5 is conducted at the end of the experimental work. Figure 6 shows the resulting titanium yield of the conducted ATR trials in different experimental scales. It is evident that the yield increases with amount of charged input material. 


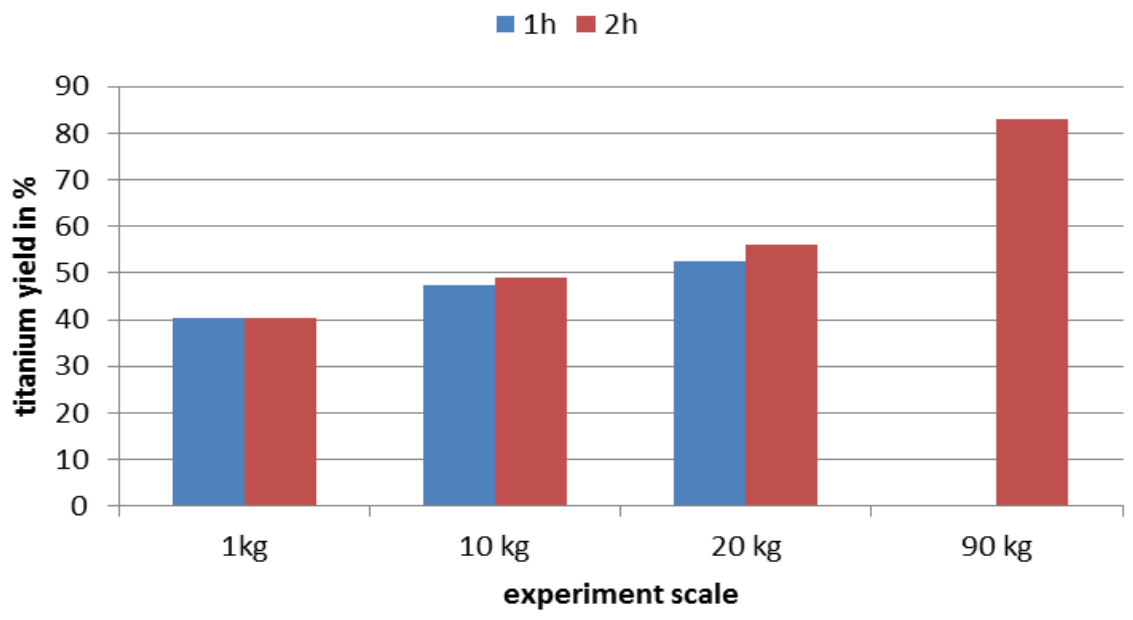

Fig. 6. Titanium yield of different experiment scales

The largest scale with $90 \mathrm{~kg}$ of charge proceeded within 2:30 min and low amount of released reaction mixture. The short reaction time offered ideal conditions for a outstanding metal-slag separation and a metal recovery of $97 \%$. At this trial the booster amount was $32 \%$ reduced compared to a reaction with non-activated rutile.

\section{Product quality}

Beside the detailed investigation of the reaction behavior with focus on reaction propagation, reaction time and metal recovery the aluminothermic trial is characterized by the quality of the alloy product. The examination of the ATR trial by the metal recovery especially in this case of the reduction of $\mathrm{TiO}_{2}$ can lead to confusions, e.g. ATR trial with $1 \mathrm{~h}$ activation time and fine Al particle size has a metal recovery of $80.2 \%$. However the chemical composition verifies that the experiment was not successful with Titanium yield $49 \%$. The residual metallic aluminum amount which is not used for the reduction of $\mathrm{TiO}_{2}$ remains in the metal phase and causes a pseudo positive ATR result during stripping the ingot.

Within the following the metal phase is analysed with SEM and EDX method. These methods offer the possibility to display non-metallic inclusions that occurs very often in the ATR process. Figure 7 shows the analysis result of the ATR trial which is conducted in the biggest scale. Spectrum 1 shows that the metal phase meets the targeted alloy composition of Ti-Al24-V16. It is also noticeable that locally the metal composition varies from the target alloy. This variance in the metal composition can be significantly decreased by further upscaling of the experiments scale. The metal phase remains in melted stage for a longer time thus homogenising the entire metal phase. 


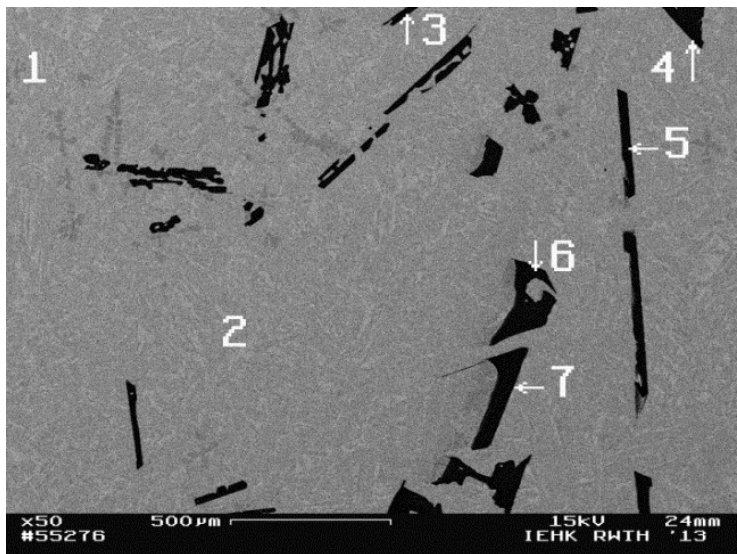

\begin{tabular}{|c|c|c|c|c|c|c|c|}
\hline & Ti & Al & $\mathbf{V}$ & Fe & Si & Cr & O \\
\hline 1 & 62.1 & 21.1 & 15.33 & 1.25 & 0.22 & & \\
\hline 2 & 51.2 & 23.3 & 22.41 & 2.14 & 0.6 & 0.2 & \\
\hline $3 / 4 / 5 / 6 / 7$ & 0.5 & 42.5 & 0.2 & 0.6 & 0.7 & & 55.5 \\
\hline
\end{tabular}

Fig. 7. SEM-EDX analysis of the up-scaled ATR trial

However the illustrated metal composition shows that this ATR product contains residual amounts of $\mathrm{Fe}$ and $\mathrm{Si}$. In fact that the ATR offers a master alloy and subsequent consolidation step to reach target alloy Ti-Al6-V4 and refining step in form of desoxidation is applied the amount of residual Fe with $1.25 \%$ would not interfere the specification of Ti-Al6-V4.

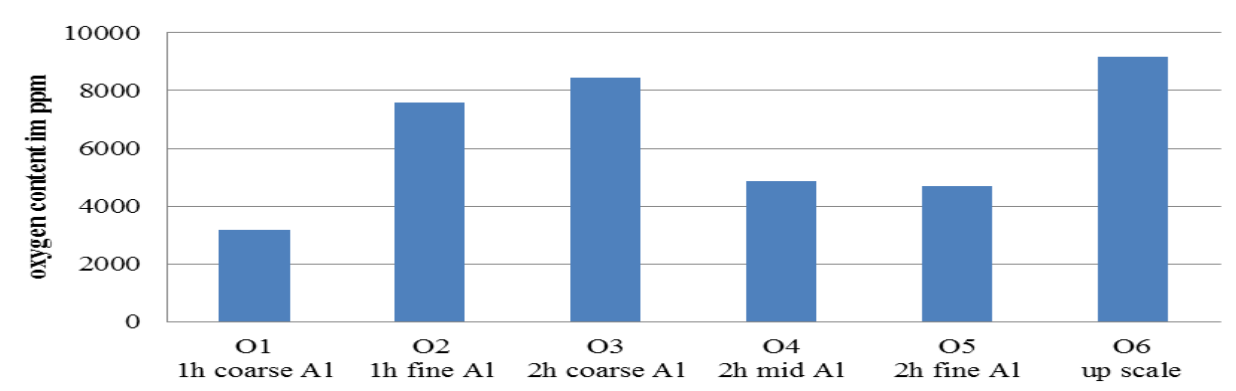

Fig. 8. Oxygen content of selected ATR trials

Figure 8 shows the oxygen content of several ATR trials. It is noticeable that the strong deviation occurs between $3000 \mathrm{ppm}$ and $9000 \mathrm{ppm}$. However compared to previous ATR trials the oxygen content is decreased from $18.000 \mathrm{ppm}$ to $9000 \mathrm{ppm}$ [10]. The specification for Ti-Al6-V4 alloys for oxygen content is $2000 \mathrm{ppm}$. Therefore a special focus lies on the subsequent desoxidation step in PESR and is under investigation as part of this project. 
The analysed composition of the metal products is given in table 4. It can be seen that in general the titanium content in the metal product is much lower than the targeted amount. Concerning the values of $\mathrm{Al}$ and $\mathrm{V}$ the results of the trials with $2 \mathrm{~h}$ activated material are close to the targeted amount.

\section{Table 4. Metal composition}

\begin{tabular}{|c|c|c|c|c|c|c|}
\hline & Ti & Al & V & Fe & Si & Cr \\
\hline $1 \mathrm{~h}$ & 41.6 & 26.6 & 13.4 & 2.4 & 1.2 & 0.2 \\
\hline $2 \mathrm{~h}$ & 47.1 & 23.2 & 14.4 & 2.8 & 0.7 & 0.2 \\
\hline $3 \mathrm{~h}$ & 41.3 & 31.1 & 13.7 & 3.0 & 0.7 & 0.2 \\
\hline
\end{tabular}

However especially the analysed $\mathrm{Al}$ contents show a large deviation of $\pm 7.9 \%$. This is due to the large amount of remained alumina particles in the metal phase, which have strong influence of the chemical analyzing method. In order to get a homogenous metal ingot the ATR product should be remelted in an induction furnace. For this process step a ceramic crucible is required that is suitable for titanium melts. The development of this ceramic crucible is part of this project and under investigation.

\section{Economic Impact}

At an economic point of view this modified process technology producing Titanium alloys via aluminothermic reaction offers following economic advantages compared to the presented process method in [10]:

- Reduction of production steps

- Charging of cost-effective rutile ore concentrates

- Reduction of $\mathrm{KClO}_{4}$ addition

- Decrease of produced KCl-gas

- Reduction of specific energy consumption

Due to the use of rutile ore concentrates the synthesis of $\mathrm{TiO}_{2}$ via chlorination is not required. The saving of expenses by using rutile ore instead of $\mathrm{TiO}_{2}$ pigment is around $50 \%$. Furthermore, the reduction of $\mathrm{KClO}_{4}$ by $30 \%$ decreases significantly the off-gas cleaning system.

\section{Conclusions}

Rutile concentrate has been successfully mechanically activated via eccentric vibrating mill. Different activation degrees of the rutile material have been provided for the aluminothermic reduction for synthesizing Ti-Al-V alloy. The focus of the experimental work was the investigation of the process parameter of the aluminothermic reaction. The results of the experiments proofed that a reduction of the booster is possible by charging mechanically activated material for $2 \mathrm{~h}$. This substitution with activated material reduces $32 \%$ of the chlorine-based booster inducing a further reduction of the produced gaseous components.

\section{Acknowledgements}

The authors would like to express their gratitude to the Deutsche Forschungsgemeinschaft for the financial support provided as a part of the Forschergruppe 1372/Titan. 


\section{References}

[1] Maeda, M.: Aluminothermic Reduction of Titanium Oxide, Materials Transactions, The Japan Institute of Metals, Vol. 34, 1993, No. 7

[2] Gock, E., Kähler, J., Vogt, V.: Produktionsintegrierter Umweltschutz bei der Aufbereitung und Aufarbeitung von Rohstoffen. In: Handbuch des Umweltschutzes und den Umweltschutztechnik, Band 2, Springer Verlag, Berlin-Heidelberg-New York 1996, ISBN 3-540-58059-X.

[3] Gock, E., Jacob K.H.: Direkter Aufschluß von Rutil mit Schwefelsäure, Erzmetall 33, Nr.6, 1980, 308-314.

[4] Gock, E.: Beitrag zur mechanischen Aktivierung von Titanomagnetit, Dissertation TU-Berlin, 1968.

[5] Achimovičová, M., Gock, E., Turianicová, E., Kostova, N.G., Velinov, N., Kaňuchová, M., Baláž, P.: Study of the mechanochemical reduction of ilmenite concentrate by addition of aluminum. In: Acta Physica Polonica A, Vol.126, Issue 4 (2014) 867-870

[6] Gock, E., v. Szantho, E.: Laugung von Rutil nach mechanischer Aktivierung in einer Schwingmühle, Erzmetall 23 (1970) 165-168.

[7] Gock, E.: Auftragsuntersuchung für die Chemetall GmbH, Langelsheim 2007.

[8] Dautzenberg, W.: Aluminothermie, Ullmanns Encyclopedia of industrial Chemistry, 1972, Vol. 7

[9] Hammerschmidt, J.: Entwicklung einer Prozessroute zur Herstellung von $\gamma$-TiAlLegierungen durch Aluminothermie und Schutzgas-Elektroschlackeumschmelzen, D82 (Diss. RWTH Aachen) Shaker Verlag, ISBN 3-8322-1971-4, Aachen 2003Stoephasius

[10] Stoephasius, J.-C.: Modelling of metallothermic reactions-local reaction rates during aluminothermic $\gamma$-TiAl-Production, Erzmetall, World of Metallurgy, Band 58,2004, Nr. 4

[11] Boldyrev, V. Meyer, K.: Festkörperchemie, VEB Deutscher Verlag für Grundstoffindustrie, Leipzig, 1973

[12] Baláž, P.: Mechanochemistry in Nanoscience and Minerals Engineering, Springer, Berlin Heidelberg, 2008.

[13] Gock, E., Kurrer, K.:Eccentric vibratory mills - theory and practice, Powder Technology 105, 1999

[14] Varma, A., Lebrat, J.: Combustion synthesis of advanced materials, Chemical Engineering Science Vol. 27, 1992, No.9-11

[15] Wang, L., Munir, Z.: Review, Thermite reactions: their utilization in the synthesis and processing of materials, Journal of Materials Science, Vol.28, 1993 